\title{
Evoking Never Never Land: The Importance of Imaginative Play and Creativity
}

\author{
Hayley Dominey
}

\begin{abstract}
This article is a condensed version of the author's research which explores the relationship between imaginative play and creativity in education, and examines the structures, approaches, benefits, and obstacles surrounding the topic of imaginative play and creativity. The photo collection is a reflection on the ponderings throughout the author's project research. Inspired by zoom-in puzzles, a similar approach was taken to the creative representation of pedagogical wonderings through a photographic journey. By looking at things from different vantage points, one can see things in different ways, and, perhaps, experience a sort of catharsis through contemplation of the overlooked in the obvious.
\end{abstract}

\section{Introduction}

This study explores the relationship between imaginative play, both inside and outside the classroom, and examines the structures, approaches, benefits, and obstacles surrounding the topic of imaginative play and creativity. In addition, insight on both the importance of imaginative play and creativity, as well as recommendations for integrating imaginative play and creativity within the Canadian elementary grades, will be discussed.

The photo collection following the research acts as a reflective commentary on some of the academic ponderings the author had throughout the project research. During the spring 2020 lockdown due to COVID-19, these ponderings came from looking at items in the author's apartment from different perspectives in relation to creativity and imagination. Inspired by zoom-in puzzle photographs, where one is tasked with identifying objects from close-up perspectives, a similar approach was taken to the creative representation of the pedagogical wonderings through a photographic journey. Only things that caught the author's attention and generated reflective thought were photographed, and this collection was limited to no more than 10 photographs of unaltered items. By looking from different vantage points, one could perceive things in different ways, and, perhaps, experience a sort of catharsis through contemplation of the overlooked in the obvious.

The key driving questions to be investigated through this study are:

1. How can imaginative play and creativity influence student engagement?

2. How might inviting both students and teachers to embrace their own curiosities and imaginations encourage creativity?

3. How does pedagogical training affect creativity in the classroom? 
4. What elements pose barriers to imaginative play and creativity, and what are some possible solutions to overcome them?

\section{Background and Significance}

How does one invite both students and teachers to embrace their natural curiosities and imaginations? I believe that one can rekindle engagement through supporting the advancement of creativity and imagination. Authors agree that children are naturally creative in their early years, and play is linked to creativity, allowing for "practice with problem solving and practice with emotions...which foster creativity" (Russ \& Wallace, 2013, p. 139). However, for many, with each year of formal schooling, these traits become dulled until they are completely dissolved by the end of their grade school journey. Clearly, even though there is a link between imaginative play and creativity, there still are obstacles to overcome to allow full educational integration. Imaginative play is also essential for all children, not just those in their early years. When children are motivated, curious, and engaged, they're also more interested in learning, and what better way to do that than to allow for what comes naturally to children: play (Ayala, 2017).

Unstructured play "can be defined as self-managed, creative, light-hearted, and spontaneous, involving rule making and breaking" (Warner, 2008, p. 1). In this form of play, the ideas come from the child's imagination, where a stick can become a sword and a tree could become a tower, all in the realm of make-believe. This may seem like something from Peter Pan's Never Never Land, but the idea of make-believe and unstructured imaginative play holds more educational importance than it's given credit. The American Academy of Pediatrics (cited in NewsWise, 2006) published a report which states that, "free and unstructured play is healthy and, in fact, essential for helping children reach important social, emotional, and cognitive developmental milestones as well as helping them manage stress and become resilient." The Canadian Public Health Association (CPHA) (2019) stipulates that unstructured play is "a child's right and a critical component to child and youth health and well-being." Yet, despite this, unstructured imaginative play struggles to be regarded as a valuable use of time during the school instructional day.

In Canada, education systems have become ever more complex, filled with a myriad of rules, regulations, and expected outcomes. The CPHA (2019) states that the average time spent at public school by students is approximately 30 hours per week, and due to growing government expectations for academic performance, pressure has been placed on many schools throughout Canada to limit the amount of free time during the school day. This leaves less time allotted for unstructured imaginative play time, despite its benefits for physical, social, and mental development (CPHA, 2019). Teachers are mandated to produce assessments and report cards, and with each grade year more expectations are added. Yet, this framework contorts authentic learning (Rule, 2006) back into a systematic form of institutionalization, reminiscent of education from the industrial revolution.

Within the current linear model of education, the intrinsic value of curiosity, the diversity of the learners, and the freedom to create, question, and explore, all become stifled in the standardized system. Thus, the 
opportunities to develop transferable skills through authentic learning initiatives are limited. This creates a static representation of possibilities for student achievement instead of a vivid array of human personalities, attitudes, and capabilities. "Human communities depend upon a diversity of talent, not a singular conception of ability. At the heart of the challenge is to reconstitute our sense of ability and of intelligence" (Robinson, 2010).

Children thrive in diverse learning environments that celebrate and explore a wide range of talents. Without acknowledging and incorporating an exploration of imagination, students are denied the opportunity to awaken and cultivate their natural talents. In effect, students' opportunities to develop their creativity, critical thinking skills, and social skills through imaginative play are lessened, and this robs them of the opportunity to develop self-agency. In addition, this over-structuring of their day may lead to higher rates of student frustration, apathy, and lack of concentration (Robinson, 2013).

Russ and Wallace (2013) postulate that it is through engaging in imaginative play that we could support the development of creativity and creative processes, as well as self-expression and interpersonal cognitive skills. They also state that we must acknowledge that, "many cognitive abilities and affective processes important in creativity also occur in pretend play and that pretend play in childhood affects the development of creativity in adulthood" (p. 136). These cognitive abilities include divergent thinking, flexibility, insight, and the ability to view things from alternative perspectives, and all are embodied through the act of creativity and imagination. Thus, with the understanding that adults evolve from their lived experiences throughout their childhood years, this vital connection to awakening one's mind must not be downplayed to lesser importance or overlooked (Russ \& Wallace, 2013).

\section{Imaginative Play in the Current Educational Landscape}

Imagination is the key to unlocking deeper cognitive functioning and the inspirational opportunities of learners, yet many educational environments seem to struggle with the ability to fully incorporate imaginative play. It is arguable that the educational landscape within Canada can be influenced by the pedagogical philosophies of teachers, the bureaucratic regulations to assert a sense of accountability, cultural influences, and even the fear for physical safety. Each plays a role in the limitations which suffocate the breath of creativity and innovation under a tightening grasp of control. Even with the best intentions to improve the quality of the education administered, the very lenses that guide educational implementation are the ones which can hinder new possibilities.

\section{Is Teacher Training Sanitizing Imaginative Play?}

There are a host of possible reasons why teachers do not extend themselves imaginatively past the training they receive during their teaching preparation. The amount of risk taken as educators can often be connected to personal experiences and philosophies, as well as where teachers are in their careers. New teachers, in particular, may not feel comfortable taking risks and could be concerned with how taking these risks would have an impact on their employability. Do teachers take risks in order to expand 
the learning possibilities, or does the possibility to deviate from a regiment act as a paralyzing agent toward the possibilities of exploration? How can perceived limitations on embracing imaginative play affect our students' abilities to flourish?

\section{Are Teachers Inspired or Merely Just Trained?}

By the time most preservice teachers enter their training programs, they have had a variety of experiences to influence their educational philosophies, and these experiences are invaluable in laying the foundation for each teacher's personal pedagogical journey. However, through their experiences within their training program, there can be an underlying message of conformity imposed upon them. Instead of encouraging innovation, creativity, and engagement, they are often confronted with the arduous task of learning to fulfill a government-mandated curriculum, and preparing assessment tools, with little emphasis on encouraging and celebrating the joys of imagination and spontaneity. Consequently, "teachable moments" become nothing more than a side-note, a whisper of something wonderful, yet seldom tapped into for fear of straying from the preset curriculum path.

Although there may be instruction on the various subject matters, much time is devoted to the idea of clustering outcomes, formulating lesson plans, and implementing guidelines to conform to a set curriculum. Before these preservice teachers step foot within the classroom to commence their practicums, they are already drilled on the necessity of assessment practices and following guidelines to fulfill outcomes. According to Egan and colleagues (2016), almost all preservice teaching is structured on an antiquated formulaic process derived from the 1960s theoretical teaching models, which themselves were based upon practices created for manufacturers during the Industrial Revolution. Lessons are structured according to outcomes, and plans are designed according to what must be taught, how it will be taught, and how it will be assessed. Everything is predetermined before there is any integration of the learners, leaving little possibility for open-ended diversity in learning.

How can it be expected for students' imaginative processes to be nurtured and developed through educational practices that do not offer the same possibilities to the teachers in teacher training programs? Egan et al. (2016) suggest parameters to reform the current state of teacher education programs to encourage imaginative pedagogy, those being "a commitment to imaginative pedagogy; a reframing of curricular methods courses; changes to field experience; and continuous, rigorous research" (p. 1005).

\section{Assessments and Accountability}

Despite a world of wonder, where creative expression, imagination, and curiosity can be prominently seen in society today, the same cannot be said for the importance of imagination and creativity in the curriculum. There is an apparent aversion to creativity and imagination having a more prominent role in education, most notably due to the uncertainties that surround how to assess the subjective and variable aspects that pertain to creativity versus, for example, literacy and numeracy (Thiessen et al., 2013). 
However, one could argue that there is an element of subjectivity and uncertainty in all subject areas, even math. Depending on the methods, thought processes, and rationale involved, one can see creativity in the approaches to solving some math problems, as well as the practical applications from this knowledge. Science requires creativity and imagination in the ability to use understanding to explore new possibilities through experimentation. Literacy, too, is brimming with the possibilities to explore, create, and wonder. All these subject areas require imagination and creativity to extend past the information learned, and to utilize these skills in real-world contexts. In basic terms, this leads to the thinking-outside-of-the-box mentality, the one which needs to be supported in education.

A broader concept of what is valuable in learning could be adopted across the spectrum of many schools. It is through imagination and creativity that a deeper understanding of self is created and through which students can make sense of the world around them. Instead of looking at the difficulties, one might reframe perspectives toward the conscious integration and encouragement of imagination and creativity throughout the curriculum. Although they require different thought processes, these are the higher-order thinking processes that allow basic skills to be used in more meaningful ways than memorization alone. This also means letting go of tight constraints on expected outcomes to allow for more ingenious exploration and acknowledging uncertainties because these uncertainties are reflective of life (Greene, 2013). Being able to embrace this fear of the unknown would drive the quest to seek knowledge, not restrain it from doing so. To allow for the possibilities of tomorrow, accommodation for creative possibilities could happen today.

\section{Encouraging an Imaginative Pedagogical Environment}

One does not exist in a vacuum, as the experiences one has both within and outside the classroom have an impact on the way one sees, experiences, and learns about the world. How does the philosophy of the school affect the mentality of the school, teachers, and students? How does community support influence the integration of imaginative play and creativity? Not all communities are the same, yet, through imagination and creativity, one can transcend the boundaries of differences. Greene presumes, "imagination opens up a plurality of experience and access to Dewey's 'great community" (cited in Heath, 2008, p. 116), and through diverse communities there are opportunities to support creative and imaginative engagement. Therefore, the outcome of community involvement depends solely upon what the learning community both within and outside of the school values and is not affected by physical location. Instead, it relies upon the community as a whole to dedicate itself toward nurturing imagination.

Societies and cultures that value imagination often have play at the center of activities, and this is where meaning is made (Huzinga, cited in Fidyk, 2019). Imagination and creation are also found to help create and foster a sense of self-completeness and growth, but to allow for this to occur, Fidyk (2019) states that we need "to welcome imagination in both play and pedagogical spaces" (p. 123). For some educational communities, this encouragement might come naturally; for others it might entail a paradigm shift in priorities. The roots of imaginative play and creativity can only grow and prosper in environments that nurture and support their existence. This includes supporting the school community and teachers through both training and resources to create the conditions conducive for imaginative play and learning.

LEARNing Landscapes | Spring 2021, Vol. 14 No. 1 | 49 
Embracing a transdisciplinary approach that blends life and learning experiences together instead of intense instruction designed to "ram and cram information to their students," places emphasis upon holistic learning through a cooperative, not competitive, environment (Colagrossi, 2018). Strong importance placed upon the arts in a multidisciplinary approach encourages imagination instead of restricting it within a systematic approach. This view of learning is more organic and appears to emulate the possibilities in the real world.

\section{When "Safety" Threaten Possibilities}

Another obstacle that could be sanitizing imaginative play is the role concern for physical safety plays in learning. Through play, children are afforded opportunities to learn valuable life lessons on how to handle risks by being "training for the unexpected" (Bekoff cited in The Strong National Museum of Play, 2020; Sandseter \& Sando, 2016). In retrospect to her own experience growing up on a Saskatchewan farm in the 80s, Fidyk (2019) reflects: "I expect my parents thought that whatever we might encounter, we could probably handle. We had grown up developing life skills that prepared us for the unexpecteda kind of natural navigation for being-in-the-world" (p. 119).

Now, the same cannot be said for children in today's learning environment. Hern states that children need the opportunity to explore, unrestrained, to make sense of their surroundings but that this "has been obscured and layered over by a noisy cultural demand for supervision and maintenance" (cited in Fidyk, 2019, p. 110). In the quest to protect students from injuries and to regulate their experiences, students are also robbed of the opportunities to learn using valuable thinking skills, skills that need to be developed and used throughout their lives. Thiessen and colleagues (2013) warn that, in the attempt to create safer learning environments, inhibition of creative thinking might also take place.

Sandseter and Sando's 2016 study states that, "outside forces in society pressure the institution to restrict physically active play" those being "local authorities, playground inspectors, the media, and parents" (p. 187). Yet with these restrictions and limitations on play, they also find that play becomes "less stimulating and challenging, and that both practitioners and children are frustrated by not having optimal play opportunities and healthy developmental conditions for children" (p. 193). Overregulation of a natural state of being kills curiosity, creativity, and imagination, limiting growth and adaptability (van der Kolk cited in Fidyk, 2019, p. 107). Sandseter and Sando (2016) finally indicate that by limiting the experiences of children, there is also a negative impact on their development as their opportunities to learn are significantly lessened.

In the end, one grapples with finding a balance between making sure children are safe, while at the same time allowing them the opportunities to grow and develop. Through their own experiences in play, children learn how to navigate new challenges. Therefore, can one afford withholding valuable opportunities from students for the sake of regulation? 


\section{Discussion}

If the purpose of education is to prepare students for the future of tomorrow, then it makes sense to equip students with the tools necessary to not only integrate and adapt within society, but to also transform that societal lens to encompass that which is yet to be; to see the possibilities and not the limitations. Perhaps the best way to argue in favor of including imaginative play and creativity embedded within our pedagogical practices is to consider what the purpose of education is in its most rudimentary sense of being. In order to encourage and support student potential, education cannot limit students to a fixed set of stagnant facts, figures, and skills. It must evoke the development of transferable skills, and creative cognitive thought processes capable of navigating new and challenging situations. It must tap into children's natural curiosities, imaginations, and playfulness and use these forms of creativity as vehicles to further propel learners toward deeper and more meaningful connections between themselves and the world. It must allow for the development of social skills, collaboration, and ingenuity, and it must allow for the natural progression of ideas without forcing a finite limit on the potential of the innate sense of wonder developed as one grows.

Through the eyes of children, we see what we could not see is already there, and this propels us to create what we thought never existed there before. To overlook a fundamentally innate human capacity is to decide to, whether consciously or unconsciously, place limits on the possibilities of what is unknown to us. We need to embrace the uncertain and cherish the opportunities for child-driven creativity and curiosities. It is through these teachable moments that some of the most important learning discoveries are created, and the most memorable experiences occur.

One such example of thinking outside the box comes from an experience I had when teaching a science lesson on identifying and categorizing natural resources to a grade five class. They were given a list of natural resources and needed to determine if they were renewable or nonrenewable, and whether they could be used for food, habitat, energy, and entertainment. If they decided that the resource could be used for each category, they had to provide an example to prove their point and be able to defend their answer with logical reasoning. When it came to the discussion over water as a resource, an interesting discussion arose around whether humans could use water as a habitat. Instantly, the majority were in agreement and said that humans could not use water in this way; therefore, it could not be included in the attributes for water. However, one student had decided that water, indeed, could be used by humans for housing.

Giggles arose about how this could be possible, and visions of humans swimming with gills emerged from students' imaginations. Yet I gently reminded the class that all great discoveries came from the ability to look at things from different perspectives and to welcome new ways of thinking. This prompted all the students to become curious as to why their fellow classmate had decided to deem water an acceptable use for human habitats. When given the chance, she explained that far north live Inuit, and in some areas there are no trees to use to make homes. There is, however, lots of firm snow from which Inuit could make igloos to live in, and since snow is made from water, Inuit make their homes from water and, thus, live in water. With the completion of her answer the entire class gasped and from their 
astonishment agreed with her reasoning. Using creative and logical thinking, she had used her understanding from other subject areas to identify a form of ingenuity which allowed her to overcome a limitation in thinking.

Through the use of a variety of creative approaches, including imaginative and creative play, one can utilize one's own imagination to support students' imaginative processes in nonthreatening ways to learn through creative means. Thiessen and colleagues (2013) state that everything one does is interrelated with creativity, and that creative skill development is essential and pertinent toward all pursuits: through the active engagement of imagination and creativity, the generation of new awareness, new ideas, and new approaches can evolve from what is known, and surpass the expected to overcome adversity and give rise to the creation of innovation and the advancement of society. Thus, creativity and imagination are important across all levels of education and are linked to the development of higher-ordered cognitive capabilities (Thiessen et al., 2013). In addition, Heath (2008) discusses how this "learning to learn" through inventiveness is "essential to [the] rapid technological development [and] cross-cultural understanding" (p. 116)

By participating in creativity in education, one can awaken "authentic appreciation" for "the sense of possibility, of what might be, what ought to be, what is not yet" (Greene, 2008, p. 17). These experiences could be evoked through a number of ways of understanding, not limited to one form of exploration or creative expression, and integrated across the disciplines. Therefore, by tapping into students' innate connection to imaginative play, they can become awakened to the world around them through their own self-connections and discoveries.

\section{Closing Remarks}

When children are invited to play unrestrained from conformities and fear, they make the environment, they learn the rules. It is only fear that holds one back from moving forward. Yet one must embrace the darkness and the void beyond if one wants to turn fear into a driving force for development, self-exploration, and the enrichment for opportunities to support a diverse and dynamic learning scape. It is also in this unknown that the greatest achievements and accomplishments are waiting to be made as "imagination makes visible what is just out of sight" (Greene, 2008, p. 19). Child exploration needs the ability to activate creativity, and this sense of wonder and curiosity can and should continue throughout life and be celebrated.

Through imaginative play and creativity, students are afforded the opportunity to explore, experience, and develop skills and thought processes. They build upon their social skills, increase their sense of selfawareness and self-expression, culture a sense of appreciation and community, and develop problemsolving skills by looking at things from different perspectives. Imaginative play fosters creativity and the opportunity for catharsis and the formation of new understandings. This is an ongoing cycle of growth, and although creativity and imagination is often viewed through a subjective lens, it may not be practical to place limitations upon these processes in the containment of what it means to be proficient. Instead, 
perhaps one needs to culturally shift the idea of what it means to learn back to the intrinsic roots of inquiry and imagination as an ongoing process.

Creativity needs to be visibly upheld as important, as echoed by Greene (1977), "all art forms must be encountered as achievements that can only be brought to significant life when human beings engage with them imaginatively" (p. 121). There is a strong connection between creativity, imagination, and play, and when supported, the possibilities for growth beyond the known is possible because the groundwork has been laid and the conditions have been created for these seeds of learning to flourish. The more one encourages imaginative play through the integration of creativity, the less foreign the concept will become in the view of educational practices.

Greene (cited by Slattery and Dees cited in Pinar, 1998) postulates that imagination is a way to liberate the structure of educational perspectives to allow for new ways of teaching, assessing, and experiencing. Rather than fear the vastness and subjectivity of imagination and creativity, one should embrace its possibilities and support this through a variety of social experiences and perspectives. Through the integration of literacy and the arts in education, along with one's own personal narratives, Greene proposes that one can create meaningful learning experiences and transform through these experiences.

If we want students to learn in a manner that will make that knowledge meaningful and memorable, we need to bring it to life for them in the context of those fears, passions, hopes, or ingenuity, either in the lives and emotions of the originators of the knowledge or in the lives and emotions of people in whom the knowledge finds living purposes today. (Egan et al., 2016, p. 1003)

And it is through imaginative play and creativity that this happen. 


\section{Appendix: Photo Diary}

\section{Foreword}

Through significant occurrences, great inspiration can hit. It was a global pandemic that not only fell under this sediment, it slammed into it. Through self-isolation I found myself questioning the role of imagination in education, and became inspired when looking at things I saw every day. I began to see things from different perspectives within the confines of my apartment and made connections between these items and the notions of imagination and creativity in education.

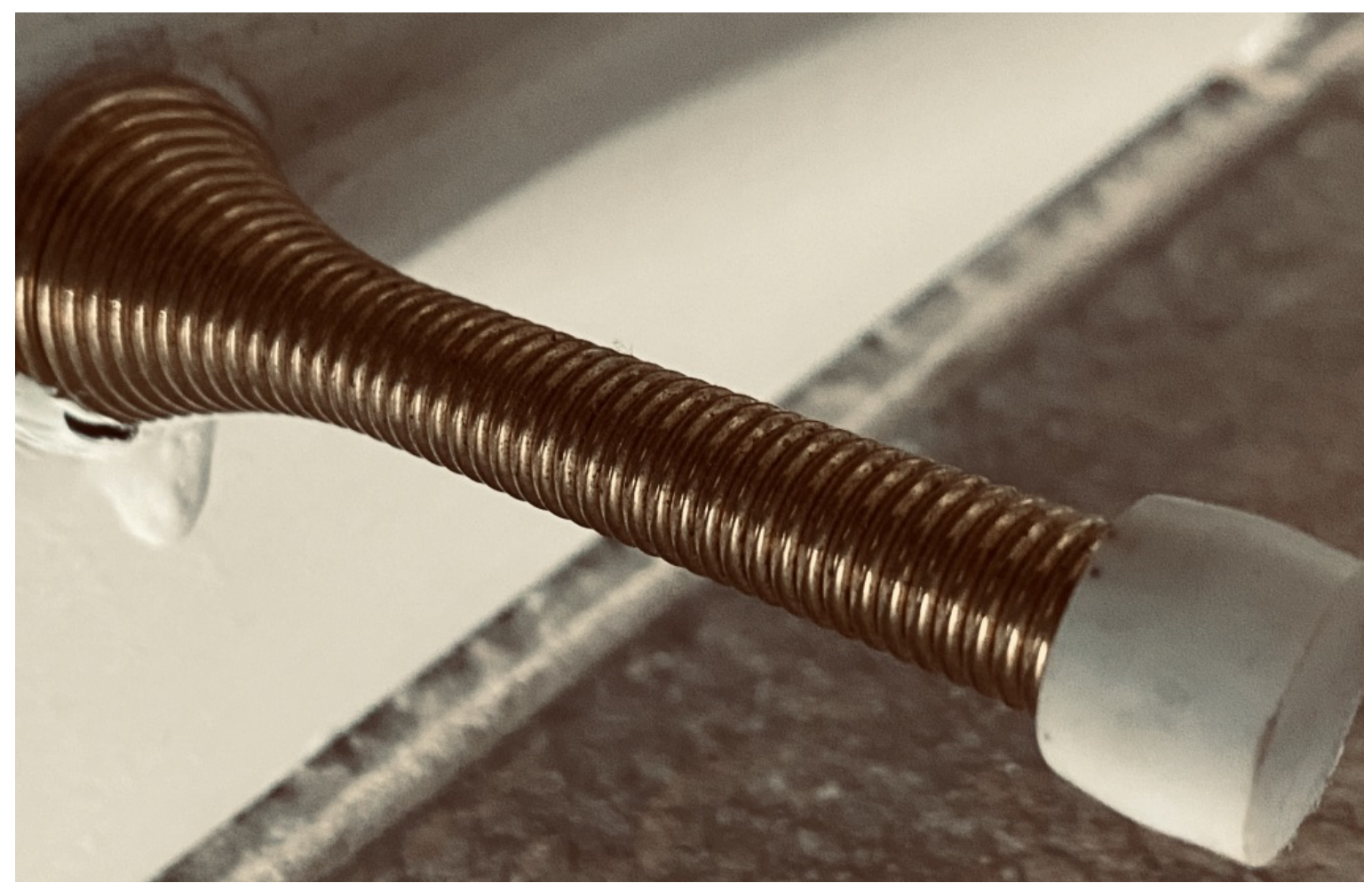

To those who are familiar, the intended purpose for this object is well known and lackluster. However, for many, it may also evoke childhood memories. For many, this was not a doorstop, but a highly technical musical instrument. Through curiosity, experimentation, and creativity, music was created, sometimes even lyrical songs. Beats, rhythm, and melodies might have developed, or perhaps even secret codes. Children didn't need to be told what its purpose was, they decided what it would be, and perhaps it would continue to be until otherwise told differently. The purpose was relative to perspectives of the engagement. I would argue that the same can be said for all children's imaginations processes. With a natural intrinsic curiosity, children could be encouraged to wonder and play, without having predetermined outcomes limit thinking. I wonder what this would look like in an educational setting; to allow curiosity and imagination to drive learning. 


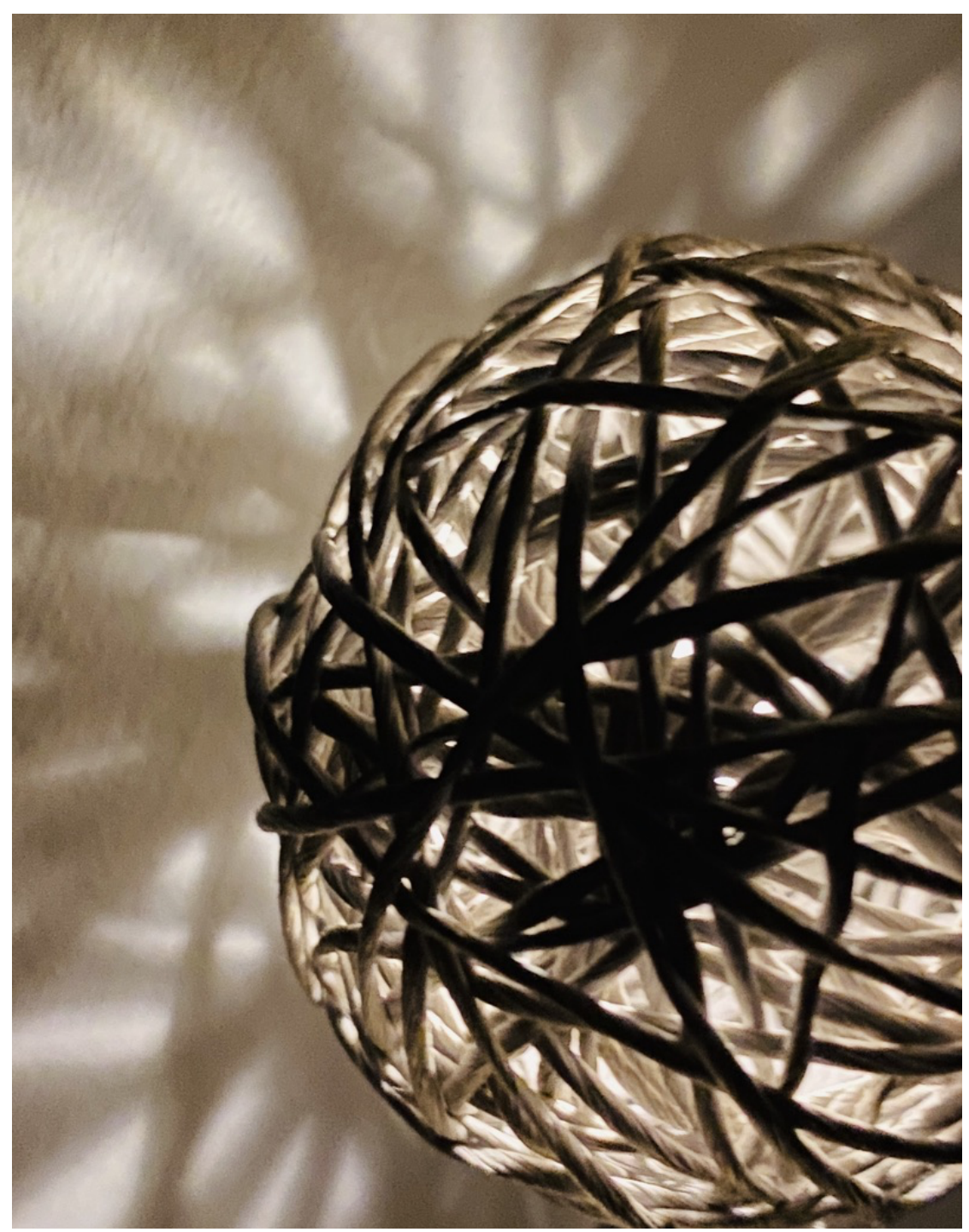

Inside the mind exists the greatest light of innovation. Curiosities are jumbled within an interwoven and chaotic labyrinth of synapses. These wonderings twist and turn, cultivating in one's mind to extend; bursting out to make their impact on the surrounding world. Ideas illuminate what might never be seen otherwise. Extending one's thoughts leads to new ways of knowing, new ways of perceiving what is seen and how to portray it. Imagination is not linear, but more complex as it overlaps and intersects with a variety of areas of cognition. This requires deeper thinking and deeper understanding. Therefore, it is understandable that there can be a level of unease on how to approach imaginative and creative thoughts because it requires more than memorizing form and function. How can imagination and creativity be supported if they are indeed at the base of learning? 


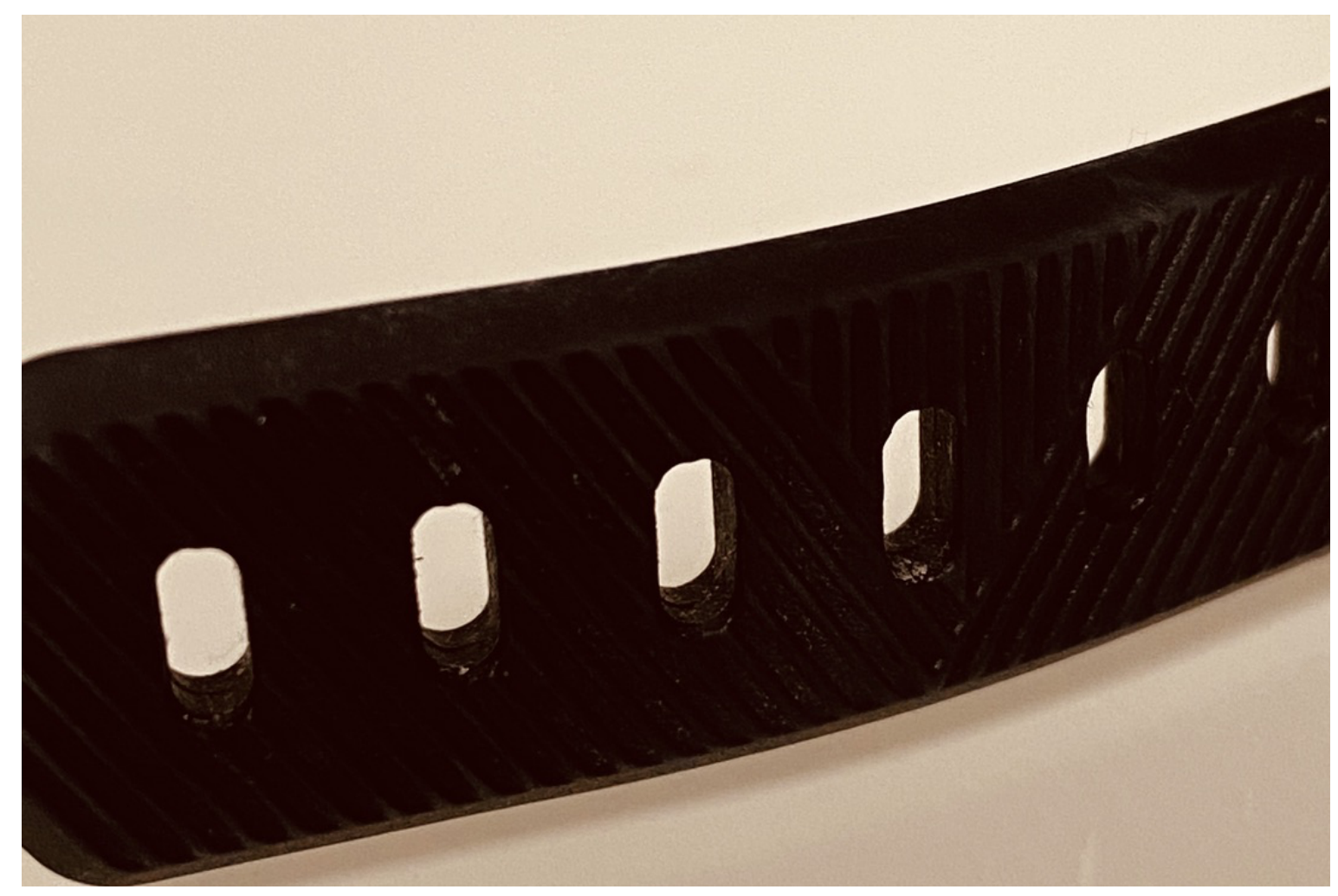

What would happen if approaches to education changed to become less linear and more flexible? With conformity and rigidity, the goal seems to be on providing progress through measurable assessments. Yet, is it possible that these perspectives limit one's overall growth and capacity? It seems that everything given educational value is placed within very standardized trajectories, which year by year lessen the incorporation of imaginative play and creativity. How could the neglect of creativity lead to adverse effects on innovation and imaginative growth? I wonder if this standardized approach could place more emphasis on the integration of creativity each year instead of less. What would happen if systems were adjusted to expand creative practices and utilize these skills instead of limit them? 


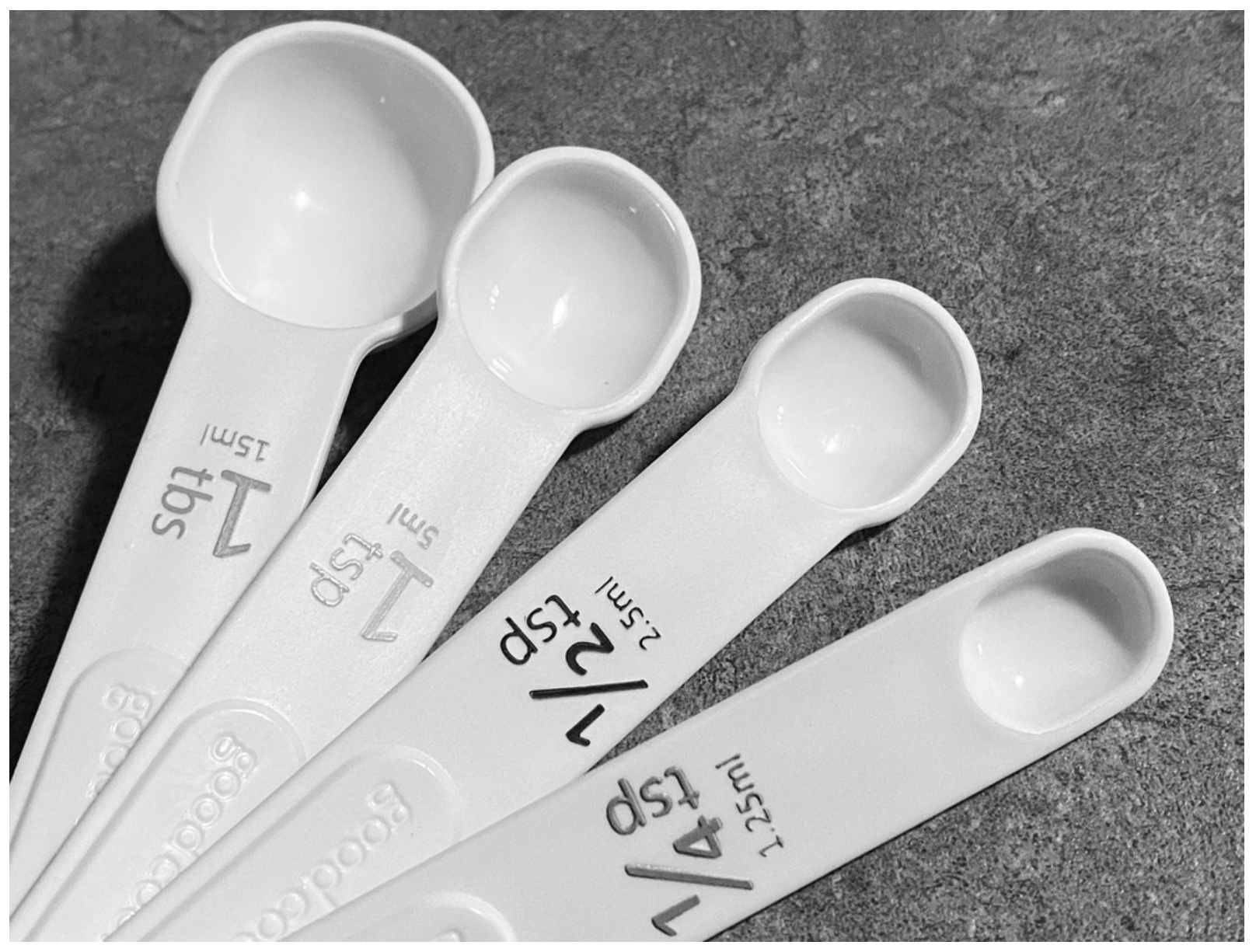

It seems as though education is regulated to fit specific measurements. All of these measurements are standardized across the curriculum and the expectations are the same. There is no dash of creativity or pinch of experimentation to create something new when this happens. Instead, there are no surprise creations, no varieties, no chances for new discoveries; just limitations to known expectations. Without the ability to explore, elaborate, engage, express, and reflect, students may be missing on all the new recipes of discovery yet to be made. There is no ability to question what you will do next, no ability to take on an unknown possibility. For whom do these recipes of learning really serve if they do not include learners in their creation? 


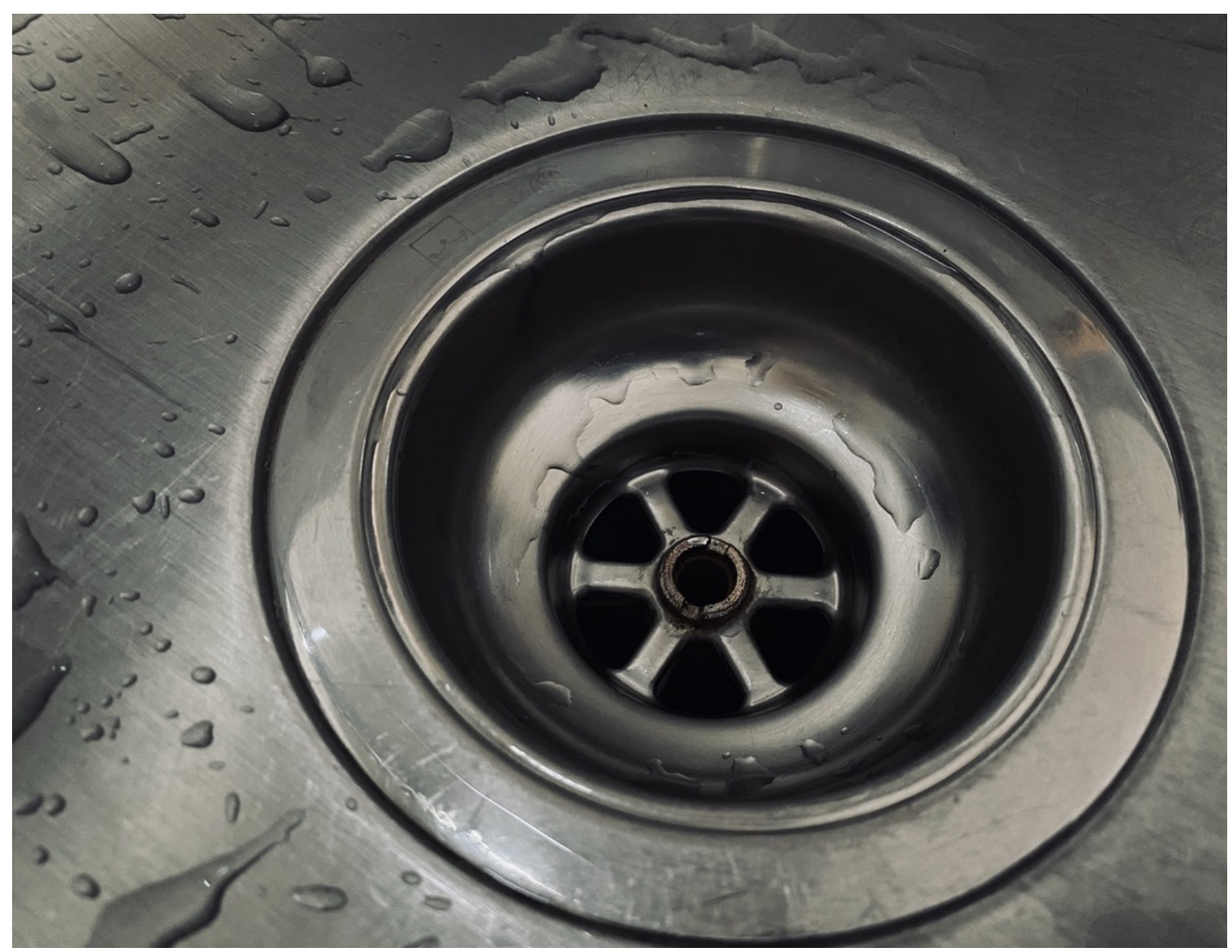

The idea of the unknown can be uncomfortable for many, yet the idea of order, structure, and efficiency can elicit a sense of comfort. The known becomes safe since events and outcomes can be anticipated. What is known is kept, what is not is flushed away. However, this can be a costly reaction in the world of education if careful attention is not placed upon what is being washed away. What is lost in this attempt to control? In many cases, great connections and extensions could be lost and unable to be brought back. The possibilities, the meaningful and teachable moments, all could slip away in the quest for accountability. This could sanitize education through the removal and aversion to creativity and imagination. 


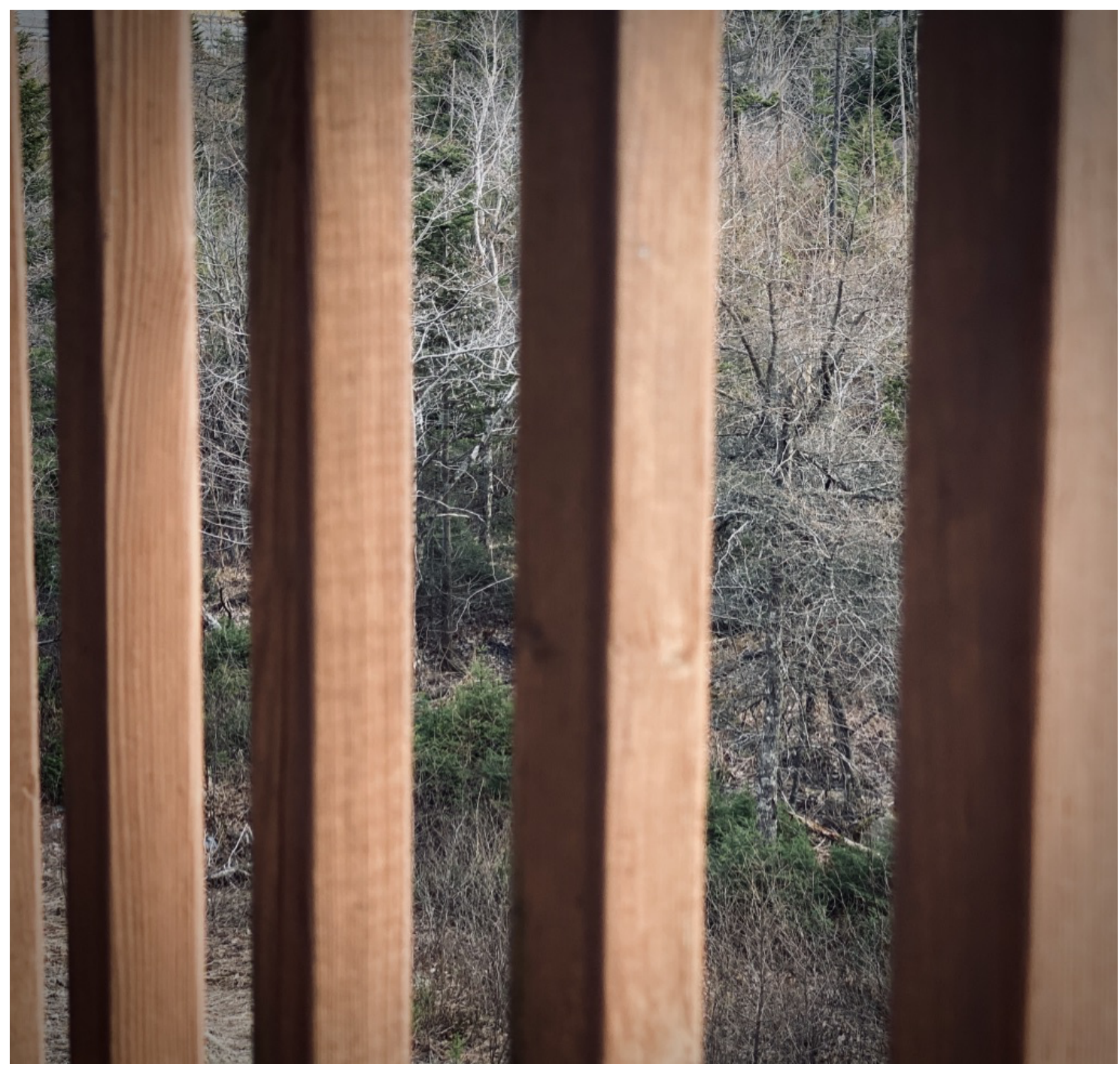

There is a disconnect in the ways many learn to teach and how education is delivered, a stark divide between the institution and the world beyond the walls. If the purpose of education is to be prepared to contribute to the world beyond, separating ourselves from the instinctual imaginative play seems counterintuitive, and unnatural. Belittling imagination and creativity from being vital connections between the inner self from the outer physical world leaves a sense of incompleteness. Looking beyond standardization, conformity, and predictability, can only strengthen a more holistic union to the organic world. How does one reach beyond the structures put in place to elicit the wonders beyond? 


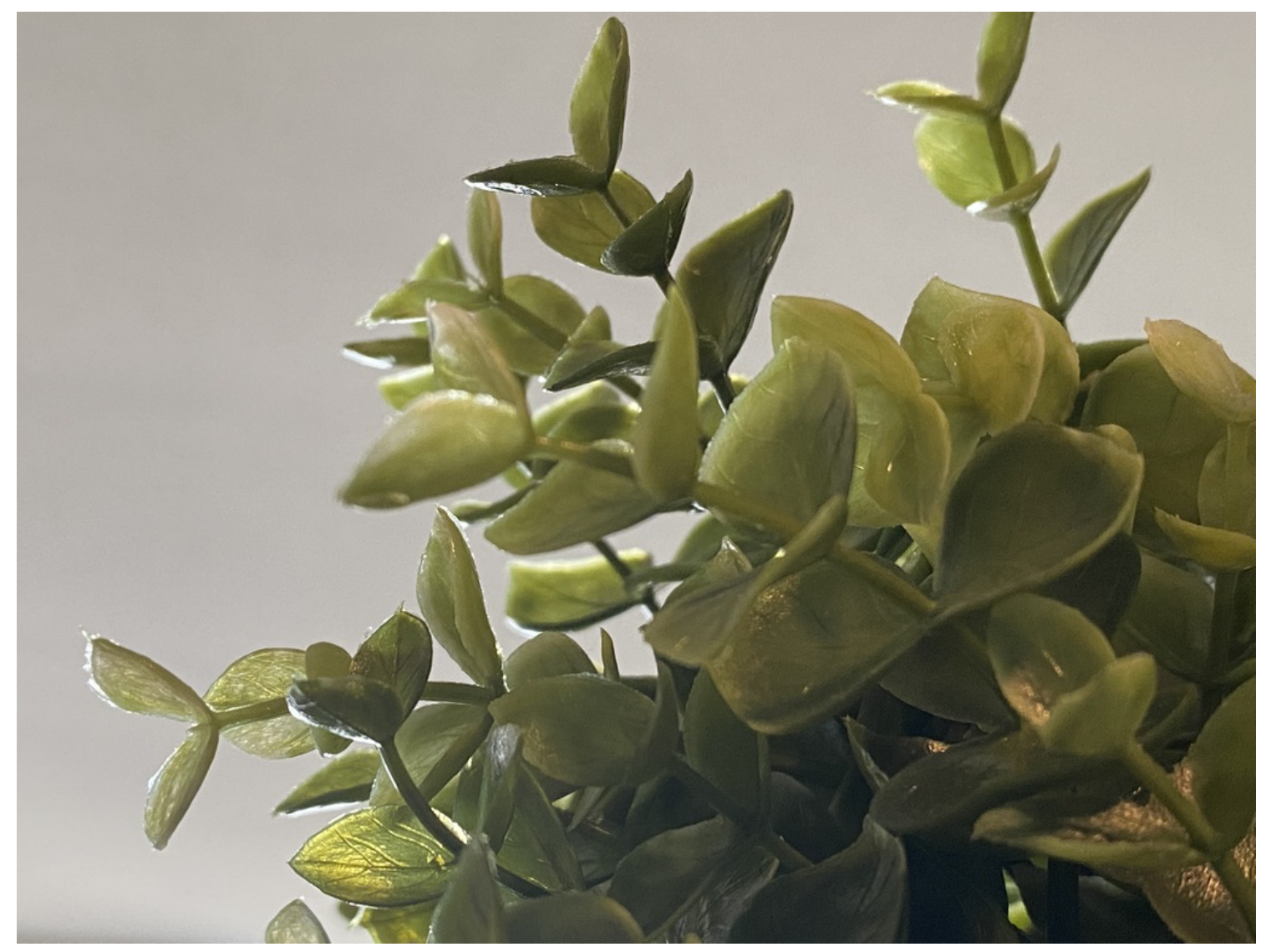

Though there is importance in standard uniformity, it does not replace the abstract variability that creative imaginative play offers. Uniformity allows for predictability, organization, structure, and control. Algorithmic functionality and systematic reproduction do provide a purpose in life and learning, but how do they expand one's capacity for growth? It is with imagination and creativity that we can use the skills and structures to create new things, to innovate, to ponder, and to explore. Creativity and imagination are the driving forces to utilize knowledge to look at the world in different ways. Through creativity and imagination, one can express innovation in various forms, and create new expressions and appreciation. 


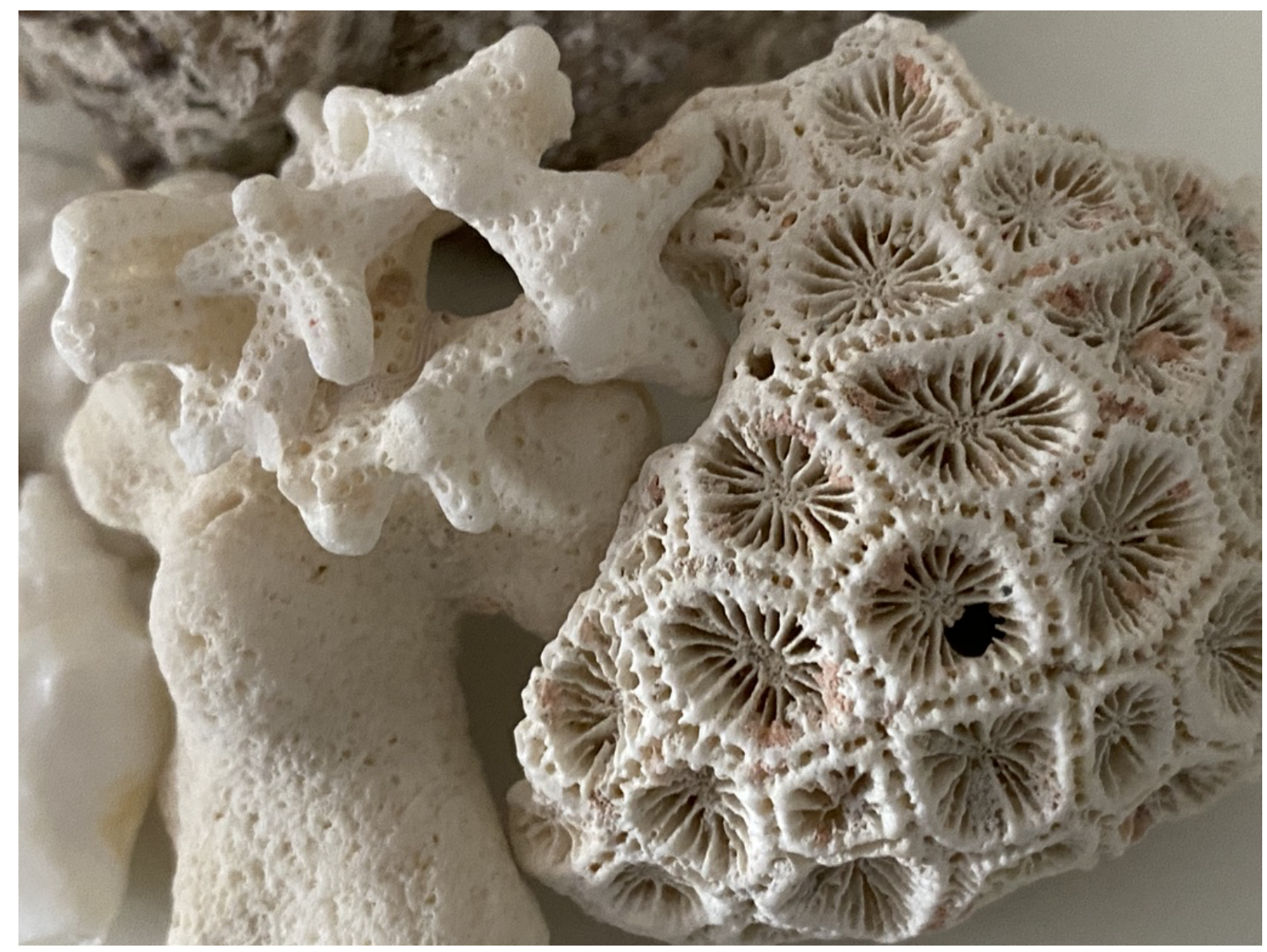

What things are overlooked when creativity and imagination are not encouraged? What interesting details, wonderous adventures, emotional developments, and inventive creations are lost? How can one take time to look closely at the value in embracing the variety afforded through imagination? Though the idea of creativity might be considered subjective, the ability to develop an appreciation for the diversity in structures, ideas, and forms opens up new ways of seeing. Diving in, surrounding oneself in the adrenaline of the possibilities, allows playful exploration to ensue. Learning through appreciating the diversity in expression could allow for better attention to the things one might otherwise miss. 


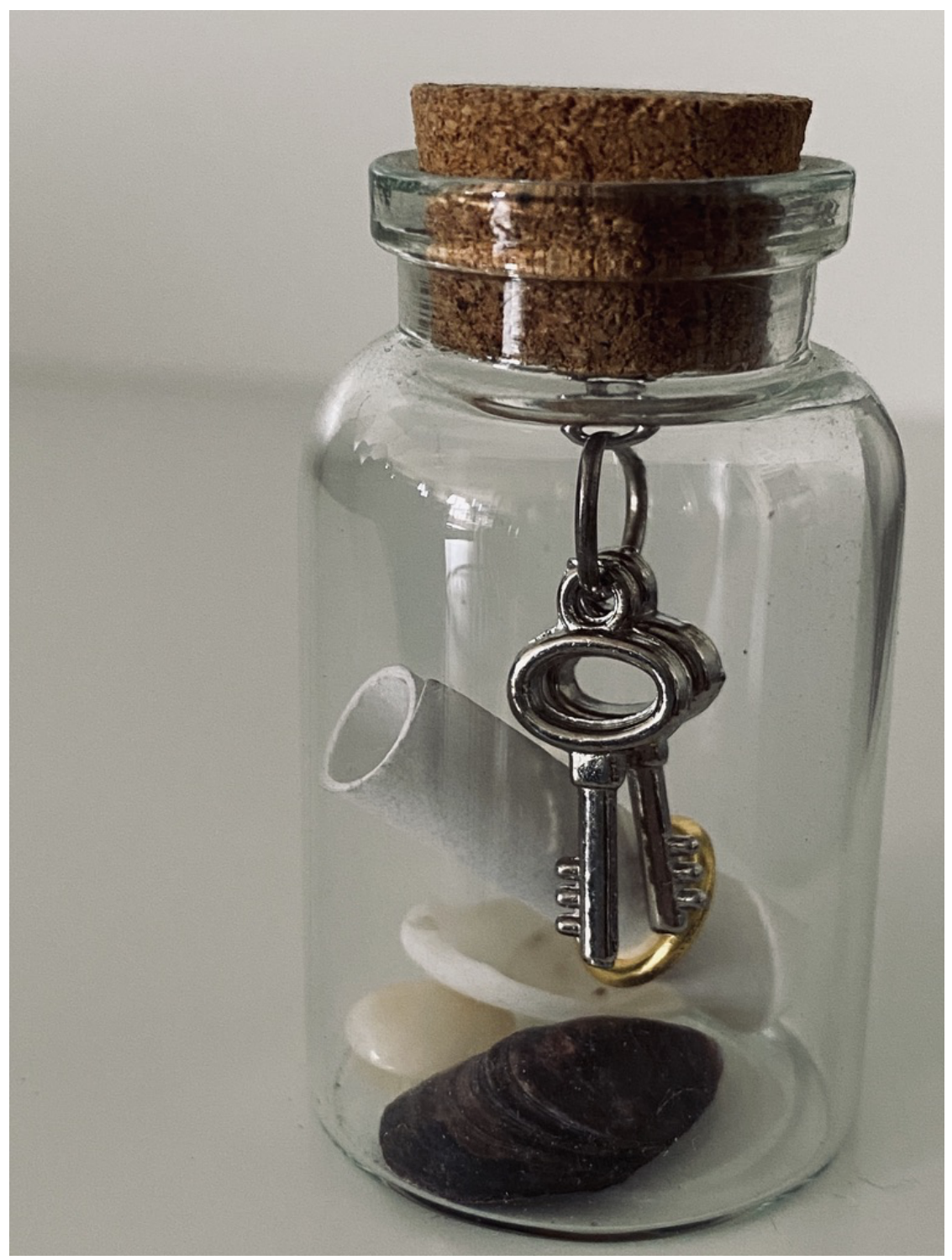

If creativity and imaginative play are important, how can they become part of the everyday educational landscape within the learning community? Everyone has thoughts, feelings, and perspectives unique to their own lived experiences, and through self-expression and exploration of these ideas, supporting the advancement of imagination and creativity can be fostered. If imaginative play and creativity are placed with lesser importance, a less encouraging atmosphere is created. The risk from this is that students bottle up their feelings, thoughts, and connections, for fear of being wrong. Instead of experimenting with being innovators, the message conveyed is that students have nothing of value to offer in their own learning journey. Thus, they keep these personal experiences and wonders to themselves. How many have fallen victim to the containment of one's own natural curiosities, and how might this be changed for future generations? 


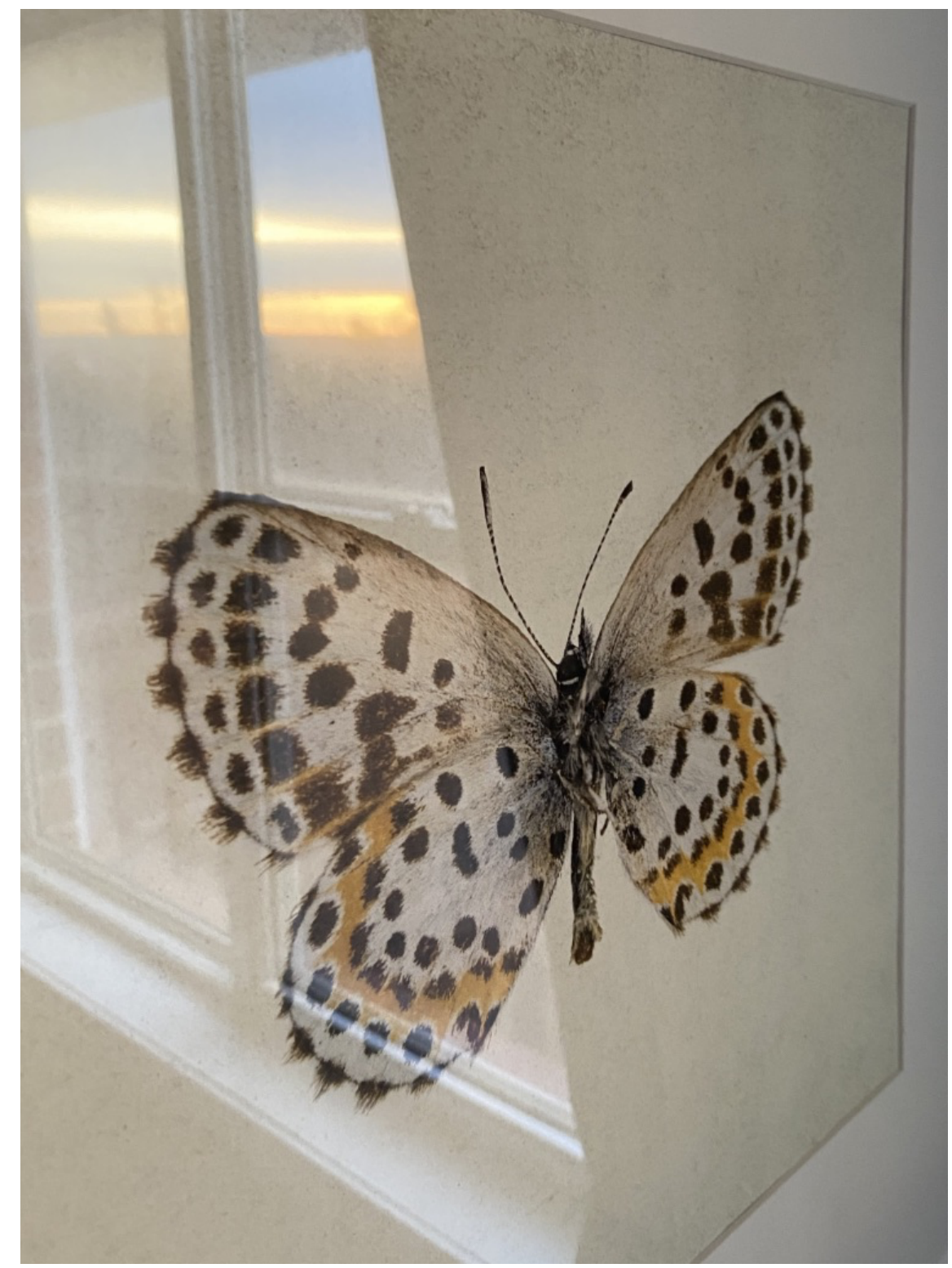

One can choose to look at things from a very literal perspective or to look beyond it to see the possibilities on the horizon. It is the creativity and imagination in the background that produces what is in one's foreground. It means digging deep into our interpretations of what is thought, what is known, and what is conjured up into being. There is a very personal component to imaginative play and creativity, thus encouragement through regular chances to explore can only lead to more possibilities for new insights and ideas. Sometimes the strangest and most bizarre creations from the mind are the most ingenious. 


\section{Final Thoughts}

One of the greatest ways to determine the calibre of a society is to observe how it chooses to approach creativity. Imagination and creativity allow one to make sense of the world and to extend from that sense toward new beginnings. It is also through creativity and imagination that many find solace and a sense of comfort, a connection between one's inner being and the outer world. At a time when there are many unknowns, it is creativity and imagination that embrace us in the solitudes and uncertainties.

Many of the pictures I chose for this pedagogical reflection portrayed the cold, linear conformity which I believe represents education in the absence of imagination and creativity. It was through these photos that I reflected upon the possibilities that waited to be created if only allowed to tap into an inner childlike wonder. Through the injection of imagination the ability to play, explore, create, and advance could come into being and create a world of possibilities.

\section{Acknowledgments}

I would like to thank Dr. André M. Comeau (Dalhousie University) for his invaluable editing assistance, and Dr. Jan Buley (Memorial University) for her steadfast support and guidance throughout the journey of this research project.

\section{References}

Ayala, D. (2017, Sept. 7). Sir Ken Robinson on how schools are stifling students' creativity. The Globe and Mail. https://www.theglobeandmail.com/news/national/education/sir-ken-robinson-on-howschools-are-stifling-students-creativity/article36205832/

Canadian Public Health Association (CPHA). (2019, Mar. 12). Children's Unstructured Play Position Statement. Canadian Public Health Association. https://www.cpha.ca/childrens-unstructured-play

Canadian Public Health Association (CPHA). (2019, Apr.). Resources and Services: Recess. Canadian Public Health Association. https://www.cpha.ca/recess

Canadian Public Health Association (CPHA). (2019). 5 Key Findings on Unstructured Play and Mental Health. Canadian Public Health Association. https://www.cpha.ca/sites/default/files/uploads/resources/play/play_5reasons_infographic_e.pdf

Colagrossi, M. (2018, Sept. 10). 10 reasons why Finland's education system is the best in the world. World Economic Forum. https://www.weforum.org/agenda/2018/09/10-reasons-why-finlandseducation-system-is-the-best-in-the-world

Egan, K., Bullock, S. M., \& Chodakowski, A. (2016). Learning to teach imaginatively: Supporting the development of new teachers through cognitive tools. McGill Journal of Education (Online), 51(3), 999-1012. https://search-proquest-com.qe2a-proxy.mun.ca/docview/1927087744?accountid=12378

Fidyk, A. (2019). Remembering childhood play. LEARNing Landscapes, 12(1), 107-124. https://files.eric.ed.gov/fulltext/EJ1245348.pdf 
Greene, M. (1977). Toward wide-awakeness: an argument for the arts and humanities in education. Teachers College Record, 79(1), 119-125. https://maxinegreene.org/uploads/library/toward_wide_wakeness.pdf

Greene, M. (2008). Commentary: education and the arts: the windows of imagination. Learning Landscapes, 2(1), 17-21. https://www.learninglandscapes.ca/index.php/learnland/article/view/Education-and-the-Arts-TheWindows-of-Imagination/270

Greene, M. (2013). The turning of the leaves: Expanding our vision for the arts in education. Harvard Educational Review, 83(1), 251-252, 266. https://search-proquest-com.qe2a-proxy.mun.ca/docview/1326778684?accountid=12378

Heath, G. (2008). Exploring the imagination to establish frameworks for learning. Studies for Philosophy \& Education, 27(2), 115-123. https://doi.org/10.1007/s11217-007-9094-7

NewsWise. (2006, Oct. 4). New AAP Report Stresses Play for Healthy Development. Newswise. https://www.newswise.com/articles/new-aap-report-stresses-play-for-healthy-development

Pinar, W. (Ed.). (1998). The passionate mind of Maxine Greene. https://doi-org.qe2aproxy.mun.ca/10.4324/9780203980729

Robinson, S. K. (2010). Bring on the learning revolution! [Video]. TED.

https://www.ted.com/talks/sir_ken_robinson_bring_on_the_learning_revolution/transcript\#t-263212

Robinson, S. K. (2013, May 10). How to escape education's death valley [Video]. YouTube. https://www.youtube.com/watch?v=wX78iKhInsc

Rule, A. C. (2006). The components of authentic learning. Journal of Authentic Learning. https://dspace.sunyconnect.suny.edu/bitstream/handle/1951/35263/editorial_rule.pdf?sequence=1\&isAl lowed=y

Russ, S.W., \& Wallace, C.E. (2013). Pretend play and creative processes. American Journal of Play, 6(1), 136-148. https://www.journalofplay.org/sites/www.journalofplay.org/files/pdf-articles/6-1-articlepretend-play.pdf

Sandseter, E.B.H., \& Sando, O.J. (2016). We don't allow children to climb trees. American Journal of Play, 8(2), 178-200. https://www.journalofplay.org/sites/www.journalofplay.org/files/pdf-articles/8-2article-we-dont-allow-children-to-climb-trees.pdf

The Strong National Museum of Play. (2020). Play quotes.

https://www.museumofplay.org/education/education-and-play-resources/play-quotes

Thiessen, M., Gluth, S., \& Corso, R. (2013, December). Unstructured play and creative development in the classroom. International Journal for Cross-Disciplinary Subjects in Education (IJCDSE), 4(4), 1341-1348. https://infonomics-society.org/wp-content/uploads/ijcdse/published-papers/voulme-4-2013/UnstructuredPlay-and-Creative-Development-in-the-Classroom.pdf

Warner, L. (Summer 2008). "You're it!": Thoughts on play and learning in schools. Horace, 24(2), 1-6. https://eric.ed.gov/?q=unstructured+play\&pr=on\&ft=on\&id=EJ849821 


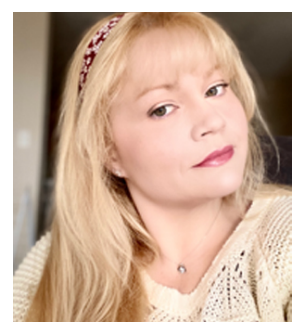

Hayley Dominey is a 2020 graduate from the Memorial University of Newfoundland Masters of Education program. Having completed her final research project under the supervision of Jan Buley (Assistant Professor, Drama, Education \& Literacies, Memorial University of Newfoundland), Hayley's final research project centered on the importance of creativity and imaginative play within education. Hayley has been a licensed and practicing educator since 2007 and has taught in South Korea, China, and Nova Scotia, Canada. In addition, she has given online presentations to first-year education students at Memorial University of Newfoundland as well as co-instructed online creativity workshops. 